\title{
Institucionalização acadêmica da História: entre o autodidatatismo e a profissionalização*
}

\author{
Academic institutionalization of History: between professionalization \\ and self-education \\ ROIZ, Diogo da Silva. Os caminhos (da escrita) da história e os \\ descaminhos de seu ensino: a institucionalização do ensino universitário \\ de História na Faculdade de Filosofia, Ciências e Letras da Universidade \\ de São Paulo (1934-1968). Curitiba: Appris, 2012, 266 p.
}

\section{Daiane Machado}

daiane_vm@yahoo.com.br

Doutoranda

Universidade Estadual Paulista

Av. Dom Antonio, 2100 - Parque Universitário

19806-900 - Assis - SP

Brasil

242 Palavras-chave

Keywords

History education; Scientific practices; History writing. 
Os cursos de graduação em História ainda são pouco explorados nas pesquisas que se dedicam à história do ensino superior brasileiro (SILVA; FERREIRA 2011). O estudo de espaços institucionais, entre eles os Departamentos de História, são observatórios do processo de constituição da história acadêmica. Escolhendo como objeto de investigação o primeiro curso nacional de História e Geografia, da Faculdade de Filosofia, Ciências e Letras da Universidade de São Paulo (FFCL/ USP), o livro Os caminhos (da escrita) da história e os descaminhos de seu ensino, publicado em 2012, está inserido, como afirma a apresentadora Marieta de Moraes Ferreira, nesse emergente, porém fecundo, campo de estudos.

Neste trabalho - fruto da revisitação de seu mestrado, defendido em 2004 - Diogo da Silva Roiz problematiza, entre 1934 e 1968, o processo de institucionalização do ensino de História e Geografia na FFCL/USP.

Na primeira parte da obra, o autor mapeia o funcionamento, os experimentos e as mudanças na estrutura curricular sob o regime de cátedras (que permaneceu vigente até 1968), entrecruzando aspectos políticos e ideológicos. Seu marco inicial foi 1934, com a instauração do Curso de História e Geografia, e o final foi em 1956, com o desmembramento dos cursos. Ou seja, trata-se de um momento chave para a organização estrutural do curso, compreendendo, mais enfaticamente, a montagem da grade curricular e a posse dos professores nas cadeiras.

Professores universitários em uma conjuntura histórico-cultural em que este tipo de ensino ainda engatinhava, pois o desenvolvimento do sistema de Ensino Superior brasileiro ocorreu, sobretudo, após a Revolução de 1930, no governo Getúlio Vargas. Vivia-se a tentativa de modernização da sociedade, paralelamente ao enfraquecimento político de São Paulo com a Revolução Constitucionalista de 1932. Foi em meio a esse cenário político conturbado que se fundou a Universidade de São Paulo (USP), a primeira universidade criada sob o regime direcionado pelo Decreto 1931 de Francisco Campos.

A meta principal do primeiro curso nacional de História e Geografia era formar professores para atender a demanda do ensino "primário" e "secundário". Questão que ficou evidente quando o autor tratou das mudanças da grade curricular implantadas por meio do decreto no 9.092, de 1946. O curso passava de 3 para 4 anos de duração com a obrigatoriedade de formação didática (teórica e prática) para os interessados em obter o diploma de licenciados. Ou seja,

[...] verifica-se que naquele período não houve margem para uma iniciação à pesquisa propriamente dita, mas as primeiras tentativas, por meio de seminários e trabalhos práticos e teóricos, de se formar, senão um 'ofício de historiador (e de geógrafo)' a partir do curso de graduação, pelo menos a iniciativa de se produzir os primeiros profissionais na área (ROIZ 2012, p. 76-77).

A formação do profissional pesquisador ainda deveria aguardar uma melhor estruturação do quadro docente. Pois bem, se havia problema com a falta de pessoal capacitado para Educação Básica, as dificuldades não foram menores para o incipiente ensino universitário. Diante dessa conjuntura nacional, quem comporia o quadro de professores? A solução foi importar profissionais, alguns, 
é necessário frisar, ainda em início de carreira, ou seja, sem tanta experiência com esse tipo de ensino. Todavia, eram sujeitos versados no mundo acadêmico e com maiores possibilidades de contato com bibliografias atualizadas da área. Com isso privilegiou-se, consequentemente, determinadas matrizes de pensamento, sobressaindo-se, devido à circulação docente, a tradição cultural francesa. Entre os pioneiros destacaram-se:

Émile Coornaert (em 1934 na cadeira de História das Civilizações, e, em 1949, como professor visitante), Fernand Paul Braudel (entre 1935 e 1937, na mesma cadeira, e, em 1948, como professor visitante), Jean Gajé (de 1938 a 1946, substituindo Braudel na cadeira, onde também orientou teses de doutoramento), Émile G. Leonard (em 1948, substituindo Gajé, mas como professor visitante) e Jean Glénisson (entre 1957 e 1958, na recém-criada cadeira de Metodologia e teoria da história) (ROIZ 2012, p. 43).

Exceção foi a cadeira de História da Civilização Brasileira. Por deliberação, ela deveria ser ocupada por um professor brasileiro, o primeiro foi Afonso de Taunay, profissional de "notório saber" entre os pares. Abordando, então, o planejamento do ensino, a perspectiva teórico-metodológica, as teses que foram orientadas e os discípulos desses professores em suas cadeiras, Roiz chama atenção para o corpo docente, composto por brasileiros e franceses, que lançaram as bases do ensino e da pesquisa histórica acadêmica no Brasil.

Nessa perspectiva, mostrou-se muito pertinente mapear o perfil e a circulação dos discentes, que, em muitos casos, tornaram-se professores do curso, dando um novo redimensionamento ao ensino e à pesquisa. Aliás, a forma de ascensão da carreira docente no período acontecia, sobretudo, pelas alianças estabelecidas durante o curso, pela aceitação no grupo. Os degraus para elevação na carreira eram a graduação, o auxílio, a assistência de ensino, o doutoramento, e, por fim, para se atingir o topo, a aprovação pela banca do concurso de cátedra. Esse foi o trajeto, por exemplo, de Eurípides Simões de Paula (orientado por Jean Gajé), catedrático de História das Civilizações; Astrogildo Rodrigues de Mello (orientado por Jean Gajé), catedrático de História da Civilização Americana; Eduardo D'Oliveira França (orientado por Eurípedes Simões de Paula), catedrático de História da Civilização Moderna e Contemporânea.

Esse não foi, todavia, o caminho de Alice Piffer Canabrava (orientada por Jean Gajé), uma vez que o último degrau não foi alcançado. O obstáculo, segundo o autor, estava numa velada "dominação masculina" entre as cadeiras. Pois,

[...] num período em que as regras do 'campo intelectual' não estavam totalmente constituídas, muito menos, amparadas sobre um grau de especialização que lhe favorecesse certa autonomia em relação aos outros campos, e, ao mesmo tempo, configurasse o formato das disputas pelo poder (Cf. BOURDIEU, 1990, 1999, 2008a), esse tipo de estratégia pôde coexistir e se reproduzir concomitantemente com a formação deste campo (ROIZ 2012, p. 37).

Pensando com o léxico de Pierre Bourdieu, Roiz procurou evidenciar quais foram as regras, assim como as brechas, que caracterizaram a configuração 
deste "campo intelectual". O caso da reprovação de Alice Canabrava (que obteve melhor desempenho) no concurso de cátedra para a cadeira de História da Civilização Americana denota as tensões e o intrincado jogo de poder no interior deste campo. O autor ainda retoma essa questão no apêndice 1, enfatizando numericamente por meio de listas de matrículas e listas de formandos o predomínio feminino existente durante a graduação, um claro contraste com a ascensão delas em nível universitário.

Se as grandes "obras de pesquisas" foram as teses produzidas para os concursos de cátedras, nos quais a participação e a aprovação feminina eram escassas, pode-se conjecturar que a escrita da História acadêmica, deste período, foi realizada com caracteres predominantemente masculinos. E, na intenção de refletir sobre os caminhos dessa escrita, Roiz escreveu a segunda parte do livro, intitulada "Escrita da história, civilização e atores sociais".

Nessa parte (que possui uma maior densidade interpretativa), o autor estudou a atuação dos docentes Alfredo Ellis Jr., Sérgio Buarque de Holanda e Eduardo D'Oliveira França,

[...] com o intuito de averiguar de que maneira inquiriram e analisaram a transição do 'autodidatismo' para a profissionalização do trabalho intelectual de História, e, nesse processo, quais caminhos propuseram para a escrita da história das civilizações e da civilização brasileira (ROIZ 2012, p. 20).

Ao se voltar para o percurso intelectual desses três historiadores, o autor enfrentou mais enfaticamente a questão que perpassa toda a obra: o surgimento do historiador profissional. Sem dúvida, uma questão premente, pois implica em um novo momento da historiografia brasileira.

Ao adentrar nas questões relativas ao ofício do historiador como as filiações às correntes de pensamento, os protocolos de leitura e de compreensão do material de trabalho (fontes), as estratégias de escrita, Roiz dialoga com Michel de Certeau, mais especificamente, com o capítulo "A operação historiográfica" do livro A escrita da história (1975).

A estratégia adotada para análise dos três historiadores foi a mesma. Primeiramente percorreu os lugares: o ambiente familiar, o de formação educacional, os espaços de circulação intelectual e de atuação profissional, e, enfim, o ingresso na cadeira. Em seguida buscou mapear as práticas científicas: princípios do ensino e da pesquisa, perspectivas teóricas e metodológicas, abordagens e tratamento das fontes. Procedimento que possibilitou ao autor compreender a escrita desses professores de História. Façamos um panorama dos três capítulos que constituem a segunda parte da obra.

Alfredo Ellis Júnior (1938-1956) foi o segundo ocupante da cadeira de História da Civilização Brasileira. O primeiro, como já mencionamos, foi Afonso de Taunay. As similitudes entre ambos são evidenciadas em seus trajetos: historiador por "vocação", Taunay fez a travessia do "autodidatismo" para a profissionalização da escrita da história; filiou-se aos princípios da historiografia positiva oitocentista e voltou-se à abordagem da história dos costumes; e, em seu 
projeto de "escrita da história" da Civilização Brasileira, partiu de uma ótica de ação paulista para compreender o passado nacional. A principal particularidade em relação a Taunay estaria na relutância por parte de Ellis Jr. em relação ao ideal de imparcialidade da escrita científica, pois para ele "o historiador pode e deve tomar partido de um problema do passado e defender a tese que tiver erigido" (ELLIS JR. apud ROIZ 2012, p. 133).

O terceiro ocupante da cadeira, também denunciou, embora distintamente, os excessos deste modelo de História dita objetiva, assim como repudiou as críticas radicais tecidas aos historiadores tradicionais, os "autodidatas". Com a aposentadoria de Ellis Jr., Sérgio Buarque de Holanda (1902-1982) ingressou na cadeira em 1956 e afastou-se em 1968, quando pediu sua aposentadoria em solidariedade aos professores de diversas universidades do país, que foram punidos por decreto do governo, incluso no conhecido AI-5. Com uma intensa atividade de trabalho jornalístico e um ganho cultural decorrido de suas viagens pela Europa, Sérgio Buarque dialogou com diferentes matrizes de pensamento, entre eles o historicismo alemão, a sociologia weberiana e os Annales. Essas leituras foram significadas em sua produção historiográfica, introduzindo discussões sofisticadas nas pesquisas em História do Brasil.

Os pontos de divergência interpretativa entre ele e os seus antecessores de cadeiras são evidentes. Segundo Roiz, Sérgio Buarque

[...] apresentava um bandeirante que, ao invés de ser um espírito aventureiro e empreendedor, nada mais fazia do que lutar contra a fome (Cf. BORGES PINTO, 1988, p. 89-92). O amor exacerbado a São Paulo levou Alfredo Ellis Jr. a escrever a história do Brasil a partir da história de São Paulo; mesmo ocupando a cadeira de História da Civilização Brasileira, suas pesquisas se concentraram na história de seu Estado. Sérgio Buarque, por sua vez, além de tratar da história de São Paulo, teve como preocupação escrever uma história do Brasil, que abarcasse as demais regiões, e em comparação com a América Latina (ROIZ 2012, p. 159-160).

A perspectiva crítica de Sérgio Buarque ao interpretar a História do Brasil abria novas possibilidades de estudos. O professor pesquisado no último capítulo também foi lembrado pelas inovações interpretativas que trouxe para o campo acadêmico. Eduardo D'Oliveira França (1917-2003), estudado entre 1942 e 1968, foi catedrático da cadeira de História da Civilização Moderna e Contemporânea. O "mestre" no ensino, como recordou o ex-aluno Fernando Novais (NOVAIS apud ROIZ 2012, p. 169), era um severo crítico da cultura geral de seus alunos e dos ditos "autodidatas".

Adepto dos Annales, França levou à sala de aula a noção de história-problema, e na obra Portugal na Época da Restauração, sua tese de cátedra defendida em 1951, trabalhou com a perspectiva da "longa duração" e a abordagem das mentalidades. Um livro essencial,

[...] sobretudo, por ter conseguido fazer não só uma reconstituição de um evento tão importante como foi a Restauração Portuguesa de 1640, mas por trazer uma discussão riquíssima sobre o Barroco, o homem do barroco 
e a civilização teatral do barroco, na qual ele faz um texto exemplar de História das Mentalidades. E o fez na década de 1950, quando esse tipo de abordagem nem era cogitada entre os historiadores brasileiros. Dividindo a obra em três partes, o autor busca articular o perfil do homem do Barroco, como um alicerce para a compreensão do processo político da Restauração Portuguesa (ROIZ 2012, p.174).

Roiz finda a narrativa sobre a produção historiográfica de Eduardo França sem esboçar um paralelo entre ele, Alfredo Ellis Jr. e Sérgio Buarque de Holanda. Dessa forma, França acaba por aparecer isolado dos demais. Embora o historiador tenha ocupado outra cadeira, um esforço de sistematização das aproximações e discrepâncias entre ele e os colegas de departamento analisados teria sido pertinente.

Esses são alguns dos pontos que instigam o leitor e, assim, revelam a complexidade dos temas que perpassam a constituição da obra. Valendo-se de um vasto e diversificado material de trabalho (obras, correspondências, testemunhos, programas de ensino, relatórios oficiais, entre outros), Roiz nos proporciona um amplo olhar sobre o processo de implantação do ensino universitário de História no Brasil, e sobre as dificuldades enfrentadas para a definição de um campo próprio de atuação profissional, tanto pela composição do quadro docente quanto pelos projetos de escrita, que envolveram filiações a correntes de pensamento. Sua obra é um convite para se desbravar o terreno ainda pouco explorado da institucionalização acadêmica do discurso histórico.

\section{Referência bibliográfica}

SILVA, Norma L. da; FERREIRA, Marieta de M. Os caminhos da institucionalização do ensino superior de História. História \& Ensino, Londrina, v. 2, n. 17, p. 283-306, jul.-dez. 2011. 